\title{
Improvising a Way Out of Darkness
}

\section{Patricia Nicholson Parker}

By mid-March 2020, we all found ourselves in the midst of a pandemic, and by May 2020, we found ourselves in the midst of an important social upheaval. The world is changing all around us, and artists are looking to find unique ways through this time that perhaps all can learn from.

Improvisation is at the heart of how I work as an artist and as an organizer. With all of the challenges that we are faced with, it is the art of improvisation that allows me to move fluidly through while keeping me in touch with the spiritual. Improvisation is not random. It is about sensing, with all of one's senses, how everything is already moving. Improvisation begins with breath-inhale, exhale - the exchange of air. It is about the spirit within and the spirit outside exchanging and about what happens in that exchange, which is everything. Change is what we are looking for, or more accurately, "transformation."

There is the constant, the breath. Everything happens within that. We can think of it in terms of the Spirit or Prana. There is a Wisdom beyond our-selves speaking through us - not just me, not just you, but through each of us. When we inhale with consciousness, we bring in Spirit and exchange Spirit.

When we interact, we are listening not only to what others are doing; we are listening for the Spirit. When we enter a room, the Spirit is already there. It is waiting for us. But it is also inside of us. It is waiting in the space where we enter. The Spirit isn't judgmental, so even when we are unaware of its existence or refute its existence, it is there. It is waiting and moving and speaking through us. What we call talent usually just describes a facility, but greatness goes beyond this; one might say that those who are great are touched. These are the ones who can truly move others. They are different, known for their uniqueness; they are not, nor can they be, normal. They must be cherished.

The music and art that is most Alive is improvisation. It is happening in and has the intensity of the moment. You can feel with your ears and your heart the Spirit in you reaching out to the Spirit in others. When you grow in your improvisation, you get to know the terrain, the language of the spirit world. But to know this world and go beyond the antechamber, you must keep entering and you must bring your listeners and viewers with you. They can also get more adept at entering this world.

A key characteristic of this world is its sense of Freedom. I believe that this Freedom is deeply connected to Love-not love for, but simply a state of Love. This space, this deepening space where all is, can only be navigated by faith. The entrance shifts and can only be accessed by sincerity. You can best enter with your eyes closed and your heart open. One might think that one must be a holy person to enter, but that is not the case. You simply must be chosen. However, those who work hard can find their way also. They too are touched or called. It is different for everyone.

The call is telling us the way of embracing uniqueness. In this view of improvisation, Unique Sound is the beginning. Thus, this music differentiates itself from the ways of pop culture-but not always. It is seldom accessed through the ways of the conservatory, which tends to hold fixed ideas of what is right or wrong.

As I said in the beginning, improvisation begins with breath: the inflow and the outflow of spirit. If 
you are performing with and for people, the spirit is strongly felt.

Thus, this time of isolation is hard on everyone whether they are making art or not. However, for the artist and for their devoted audience-those who have been traveling internally with the music and art-it is a devastating deprivation.

This has also been a time for deep inward reflection so that, when the artist returns, it is very likely that the Art will be that much stronger-for those who make it through. This time challenges us. It gives us Time, but it deprives us of most everything else, such as money, emotional support, the enrichment of being inside our Art in Public with the accompanying exchange of Spirit and the physicality of friendly encounters. Yet here we are. As Improvisers, we shift as time and circumstance shift. After all, that is our medium: the shifting language of spirit-driven choices.

Now we have added to the casualties of pandemic the growing outrage over the continuing immorality of racism and classism, as well as a general degradation of the sacredness of Life itself. This is legitimized by leadership that lacks a moral compass. This is not a vague reality for people of color, particularly African Americans, Indigenous people, and any who are outside of the white middle class norm. These attacks prove a spiritual and moral blindness that, like any disease, is spreading.

There is the attack on truth which makes truth irrelevant. The fact that these attacks are coming from the president of the United States is a powerfully bad example. So, there is an uprising of moral indignation, of anger over injustice, etc. Artists are playing their part based on their unique personalities, as are the organizations that present them. But inside each one is the possibility of Spirit talking through and the deep sincerity felt through each note played, through each gesture of the dance, through the flow of text as poem and the stroke of the painter's brush.

As an artist and an organizer, I try to let my voice be heard through everything that I do, through my art as well as through supporting those artists that I present, never stopping, never forgetting, trying to be a loving presence in my community.

The Community of artists who I have heard from have expressed their concerns about:

- Loss of jobs for musicians and all that comes with it,

- Closing of venues,

- Closing of organizations,

- Audiences losing interest in live performances,

- How long it will take before they can perform live,

- The psychological and emotional welfare of younger musicians from the trauma of COVID-19 and the struggle for justice,

- Fear of political pushback, knowing the history of the government's response to resistance that threatens white supremacists,

- The importance of the individual and intimate connections, the 1 to 1 , those small actions that keep us together,

- Deep sadness and depression that it will never change and that we as a society have gone too far, 
- Education of young people suffering and art education in particular taking the biggest hit just when it is most needed,

- The growing gap between rich and poor,

- The sustainability of the fight for justice — that people will give up,

- Housing - not being able to pay rent with so much loss of income,

- Being unsure of the difference between playing music and protesting,

- Being unsure as to how they can be effective,

- How to care for one another as well as themselves,

- Bringing to light the power of diverse crowds of people coming together in protest,

- The importance and need for historical context for today's struggles,

- Focusing on our strengths and moving forward from there.

Each artist will bring their own answers and each organization will find solutions. I believe that we will increasingly find new ways to keep improvising in ART and LIFE, in order to find our way out of this darkness. 